\title{
Carbonated miscanthus mineralized aggregates for reducing environmental impact of lightweight concrete blocks
}

\author{
Luc Courard ${ }^{1, *}$ and Véronique Parmentier ${ }^{2}$ \\ ${ }^{1}$ University of Liège, Research Unit Urban and Environmental Engineering, Liège, Belgium \\ 2 Bureau d'expertise JM Rigo, Verviers, Belgium
}

Received: 7 December 2016 / Accepted: 16 March 2017

\begin{abstract}
At a time when the cement industry is largely responsible for the production of $\mathrm{CO}_{2}$ in the construction sector, it is useful to make this production a reverse phenomenon: that is $\mathrm{CO}_{2}$ capture. The $\mathrm{CO}_{2}$ absorption process called carbonation, improves specific properties of the concrete during the conversion of carbon dioxide $\mathrm{CO}_{2}$ into calcium carbonate $\mathrm{CaCO}_{3}$. Current environmental concerns motivate the study of carbonation in order to maximize the absorption of carbon dioxide. Moreover, lightweight concrete with biobased products knows an interesting development in the construction field, especially as thermal insulation panels for walls in buildings. Before identifying and quantifying the basic physical characteristics of concrete made from miscanthus, it is necessary to optimize the composition of the product. The long-term stability as well as the reinforcement may be obtained by means of a mineralization process of the natural product: a preparation with a lime and/or cement-based material is necessary to reinforce the cohesion of the bio-based product. Mineralization process is described as well as the way of producing blocks for $\mathrm{CO}_{2}$ capture by means of accelerated carbonation. Finally, concrete blocks produced with miscanthus mineralized aggregates offer interesting mechanical properties and minimal environmental impact.
\end{abstract}

Keywords: miscanthus / mineralization / concrete / absorption / carbonation

\section{Introduction}

The construction sector is one of the largest and most active sectors in Europe. In environmental terms, it represents $30 \%$ of carbon dioxide total production (2009). In the construction industry in general, selection of materials and waste management absolutely require a global reflection, from bottom (operations, resource processing and materials chemistry) and top (recycling, waste management). This is especially true as new modes of design in the construction industry (passive or positive energy buildings) require the use of materials whose energy impact should be minimized [1].

Concrete products are sustainable building materials. Their compositions are based on natural, abundant and locally available raw materials. The concrete block manufacturing requires low cement content and almost no energy during the curing phase - there is no baking which greatly limits $\mathrm{CO}_{2}$ emissions.

At a time when the cement industry is largely responsible for the production of $\mathrm{CO}_{2}$ in the construction sector, it is useful to make this production a reverse

\footnotetext{
* e-mail: Luc.Courard@ulg.ac.be
}

phenomenon: that is $\mathrm{CO}_{2}$ capture. The $\mathrm{CO}_{2}$ absorption process, called carbonation, improves specific properties of the concrete during the conversion of carbon dioxide $\mathrm{CO}_{2}$ into calcium carbonate $\mathrm{CaCO}_{3}$. Current environmental concerns motivate the study of carbonation in order to maximize the absorption of carbon dioxide.

Finally, the use of bio-sourced aggregates such as miscanthus plant will decrease again the environmental impact of concrete blocks manufacture and increase insulating properties.

\section{Principles and advantages of carbonation}

Carbonation is a chemical reaction between the cement paste and hardened carbon dioxide [2]. This reaction can occur in a mature concrete between the hydrated products (CSH and $\left.\mathrm{Ca}(\mathrm{OH})_{2}\right)$ and $\mathrm{CO}_{2}$ (Eqs. (1) and (2)). The carbonation can also take place in the presence of moisture between the hydraulic components of clinker $\left(\mathrm{C}_{3} \mathrm{~S}\right.$ and $\left.\mathrm{C}_{2} \mathrm{~S}\right)$ and $\mathrm{CO}_{2}$ (Eqs. (3) and (4)). The carbonation of a mature concrete has the effect of decreasing the $\mathrm{pH}$ of the concrete pore solution which eventually may promote corrosion of reinforcing steel; several studies have been conducted to slow this mechanism and protect the frames [3]. 
The proposal made here is to induce early carbonation by infusing $\mathrm{CO}_{2}$ immediately after release. Products of the reaction are a mixture of hydrates and hybrid carbonates (Eqs. (3) and (4)). In the case of application without steel reinforcement - such as concrete building blocks - the carbonated products are improving concrete performances in terms of strength, durability and dimensional stability, thanks to the lower content or disappearance of $\mathrm{Ca}(\mathrm{OH})_{2}$.

$$
\begin{gathered}
\mathrm{Ca}(\mathrm{OH})_{2}+\mathrm{CO}_{2} \rightarrow \mathrm{CaCO}_{3}+\mathrm{H}_{2} \mathrm{O} \\
3 \mathrm{CaO} \cdot 2 \mathrm{SiO}_{2} \cdot 3 \mathrm{H}_{2} \mathrm{O}+3 \mathrm{CO}_{2} \rightarrow 3 \mathrm{CaCO}_{3}+2 \mathrm{SiO}_{2} \cdot 3 \mathrm{H}_{2} \mathrm{O}
\end{gathered}
$$

$$
\begin{aligned}
2\left(3 \mathrm{CaO} \cdot \mathrm{SiO}_{2}\right) & +3 \mathrm{CO}_{2}+3 \mathrm{H}_{2} \mathrm{O} \rightarrow 3 \mathrm{CaO} \cdot 2 \mathrm{SiO}_{2} \cdot 3 \mathrm{H}_{2} \mathrm{O} \\
& +3 \mathrm{CaCO}_{3} . \\
2\left(2 \mathrm{CaO} \cdot \mathrm{SiO}_{2}\right) & +\mathrm{CO}_{2}+3 \mathrm{H}_{2} \mathrm{O} \rightarrow 3 \mathrm{CaO} \cdot 2 \mathrm{SiO}_{2} \cdot 3 \mathrm{H}_{2} \mathrm{O} \\
& +\mathrm{CaCO}_{3} .
\end{aligned}
$$

The carbonation process has been studied in order to improve the dimensional stability of concrete building blocks. Indeed, the hardened cement paste reacts with atmospheric $\mathrm{CO}_{2}$, which can lead to problems of withdrawal. In the U.S., the NCMA (National Concrete Masonry Association) and the PCA (Portland Cement Association) have conducted research in 1963: the concrete blocks were first subjected to moist air between 80 and $100{ }^{\circ} \mathrm{C}$ for $5-18 \mathrm{~h}$. Then, after $24 \mathrm{~h}$ or 4 months, they were stored a high atmospheric $\mathrm{CO}_{2}$ [4]. This helped to reduce shrinkage of about $30 \%$. But the energy consumption of this process is enormous.

During seventies, mechanisms of carbonation were studied in relation with reactivity and strength of calcium silicate activated by $\mathrm{CO}_{2}$ [5]. This technique was introduced for the production of panels cement fibre based, in order to reduce the manufacturing time; the first plant operating on this principle was built in Hungary in 1985, but was closed for reasons of cost of $\mathrm{CO}_{2}$.

A feasibility study of $\mathrm{CO}_{2}$ sequestration through a technique of accelerated cure was conducted at McGill University (Montreal, Canada) between 2004 and 2006 [3]. The possibilities of fixing $\mathrm{CO}_{2}$ in cement matrices were explored and performances in the short and long term implications were verified: it showed some interesting opportunities offered by this technique, based on specific accelerated carbonation process.

Currently, concrete blocks are produced on a wet cure (water vapor) based process. It is estimated that for $1 \mathrm{~m}^{3}$ of concrete blocks manufacturing, wet cure at atmospheric pressure consumes 0.59 GJ while curing in autoclave consumes 0.71 GJ [3]. If a $\mathrm{CO}_{2}$ injection process is put in place, for the same volume of concrete, the energy for recovery and compression of $\mathrm{CO}_{2}$ is estimated to be 0.02 $0.10 \mathrm{GJ} / \mathrm{m}^{3}$, for a minimum value of $\mathrm{CO}_{2}$ capture into cement of 10 and $50 \%$, respectively. That means that the total energy, excluding $\mathrm{CO}_{2}$ transport necessary to carbonation, is significantly lower than that required for a traditional wet cure.
The building blocks of concrete are particularly suited to carbonation, because of their mass production, their high porosity and the need to practice a wet cure. The reaction between the cement paste at early age and carbon dioxide thus constitutes a form of $\mathrm{CO}_{2}$ sequestration. If we consider a hollow block $39 \mathrm{~cm} \times 19 \mathrm{~cm} \times$ $19 \mathrm{~cm}$ and $18 \mathrm{~kg}$, which contains about $10 \%$ by mass of cement, we can consider that it is able to fix at least $0.18 \mathrm{~kg}$ of $\mathrm{CO}_{2}$ [3]. If the cement is replaced by slag, the capture rate will remain about the same [6]. Furthermore, if the aggregate ( $86 \%$ by mass) are also used to fix $\mathrm{CO}_{2}$, the fixed amount considerably increases. Carbonated steel slag could set another $6 \%$ by mass. Therefore, if one considers that each aggregate is able to fix about $5 \%$ of its mass in $\mathrm{CO}_{2}$, a total sequestration of $0.77 \mathrm{~kg}$ may be attempted, for aggregates and a block. A block of concrete construction would be potentially able to fix $0.95 \mathrm{~kg}$ of $\mathrm{CO}_{2} ;$ as production of concrete blocks in Belgium is 3.36 million tons per year (www.febe.be), it is estimated that the amount of $\mathrm{CO}_{2}$ fixed could be 16,800 tons, if only $5 \%$ of the Belgian market is concerned in a first step. On the other hand, considering that $1 \mathrm{~m}^{2}$ wall consumes $12.5(39 \mathrm{~cm} \times 19 \mathrm{~cm} \times 19 \mathrm{~cm})$ blocks, we can estimate that each $\mathrm{m}^{2}$ of wall will be able to capture $2.25 \mathrm{~kg} \mathrm{CO}$. For comparison, in Canada and the USA, the annual sequestration potential is estimated at 3.2 million tons [3].

This concept could lead to term, if based on the judicious choice of materials for the "aggregate" part, to a situation of "zero-emission". This will be the case if biosourced or recycled aggregates can be used [7-9]. Moreover, the accelerated carbonation blocks should lead to improved mechanical performances, lower porosity and a reduced risk of efflorescence: the denser microstructure of concrete, which improves the durability of the product and, therefore, the duration of life. Finally, the developed industrial process does not change the potential for recycling at end of life, particularly in the manufacture of new blocks. The objectives of the present research are to study the opportunity of the capture of $\mathrm{CO}_{2}$ in concrete blocks with miscanthus mineralized aggregates. Mineralization process is described as well as the way of producing blocks for $\mathrm{CO}_{2}$ capture by means of accelerated carbonation.

\section{Materials}

\subsection{Miscanthus original aggregates}

\subsubsection{Description of the plant and mineralization}

Compared to the hemp plant (annual) [10,11], miscanthus (Fig. 1a) is a perennial plant, located for several years (up to 20 years for miscanthus), which reduces costs of crop establishment: energy consumption is evaluated around $9223 \mathrm{GJ} / \mathrm{ha}$ (for hemp: 13,298 GJ/ha).

In comparison with wood, miscanthus has a high content of parenchyma, surrounded by a tough fibrous structure. It therefore combines a high rigidity with a low density [12]. The modulus of elasticity of Miscanthus giganteus and Miscanthus sinensis vary between 2 and $8 \mathrm{GPa}$ [13]. 


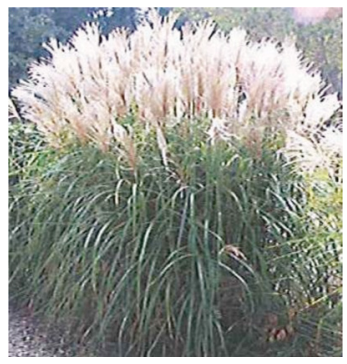

(a)

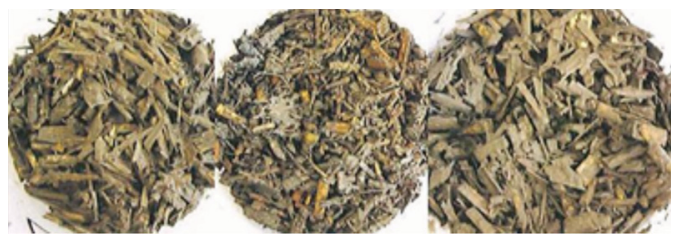

(c)

Fig. 1. Miscanthus malepartus (a) plant, (b) chips and (c) chips after mineralization.

The strength and the physical properties of agromaterials are coming from their ultra-structure (Fig. 1b). The different layers that constitute the cell wall of plant [14] show the complex interactions between the cellulose material and binder necessary to combine these particles and homogenize the behavior of the finished material. In our case, the inorganic binder, based on hydraulic or pozzolanic products, offers a variable behavior depending on water content but also on sugar or carbohydrates concentration. Wooden structure is a highly porous and very durable material but it seems essential to be treated before used as aggregate in concrete [14]. Indeed, without woodchip pretreatments, the mixtures offer unstable results [15]. In addition, the stability of the concrete cannot be achieved because untreated chips react chemically with the environment and dimensions considerably vary with changes in humidity. In order to increase the durability of the composite and to reduce vapor or liquid transfers between the chips and their environment, the mineralization appears to be the best solution (Fig. 1c).

This treatment consists in soaking the chips with a mineral solution; a mixing procedure of about 3 min allows an impregnation of the chips. Currently, the components used for mineralization are mainly calcium chloride, silica fume and derivatives of lime and cement. However, the composition of the "mineralizing" ideal solution is not yet clear defined and mainly depends on the type of plant. For example, the external wall around miscanthus chip (Fig. 2) is more impermeable than for woodchip: that means that the penetration of the mineral solution into the external layer will be less efficient but needs to be adapted.

The type of mineralization is obviously an important factor to be considered: the products on the market are cement, but also lime and by-products of the steel industry, electricity production (ash) or extractive industries (limestone filler). For applications in building interior, the use of gypsum waste may be also considered. The

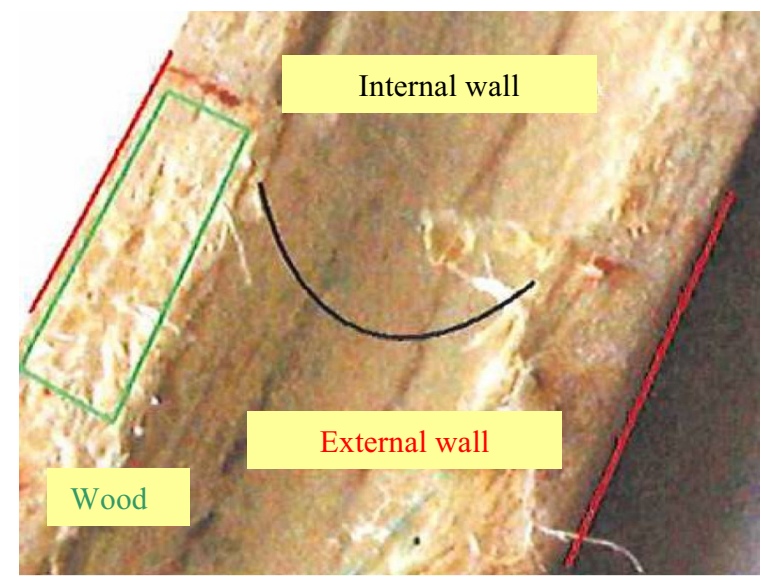

Fig. 2. External wall of a miscanthus chip [15].

studies conducted until now $[14,15]$ promote the use of mixtures of cement and lime. The various stages will allow playing on the parameters of mixes in order to meet the physical, chemical and mechanical minimum requirements: - compatibility between selected species and different mineralizing agents;

- measurement of setting time of different mixtures;

- study the thermal effects of the hydration reaction of the binder on the penetration of fine particles into plant chips, compressive strength at short, medium and long terms.

\subsubsection{Analysis of mineralization effects}

Miscanthus chips have been observed under optical microscope. Chips are impregnated with resin and polished. After optical examination, specimens are metallized with platinum and introduced into the vacuum chamber of the Field Emission Environmental SEM Philips XL30 (ESEM) [7].

First investigations are realized with optical binocular microscope (Fig. 3a). Plant is covered with a cement-based hardened material whose thickness varies from 0 to $1 \mathrm{~mm}$. This thickness is variable and does not seem to depend on the type of the material: it seems however be strongly influenced by fragmentation, granulometry and the porous structure of exposed faces.

The porosity of the external wall in miscanthus chips (Fig. 3b) is low. It is mainly due to the fact that miscanthus chips are produced by cutting rods in small pieces. The integrity of the external wall, which is impermeable, may be preserved after cutting.

Chips are very sensitive to variation of humidity. If water content is less than the Fiber Saturation Point (commonly 25-32\%), shrinkage may induce cracks. Although a few peripheral cells of the chips are met by mixing cement, no penetration of the internal cells was observed (Fig. 3b). The adhesion of cementitious mineralization is superficial and essentially depends on the porosity of surface of walls.

Plant materials conserve their internal porous structure, which is a main objective for promoting lightweight and thermal insulating aggregates. 

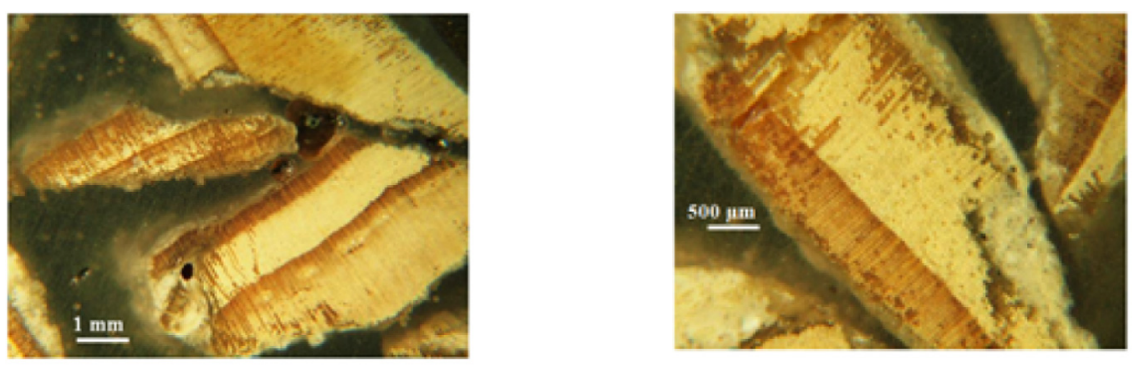

(a) optical microscope view
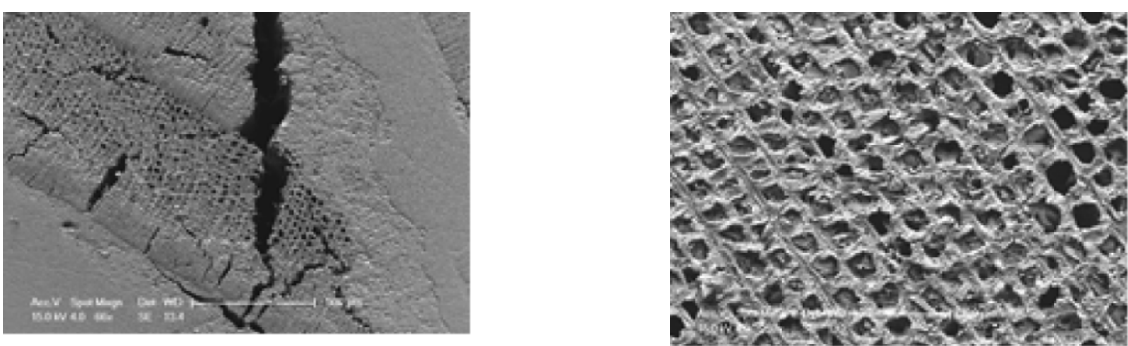

(b) SEM view

Fig. 3. Miscanthus after mineralization.

Table 1. Apparent density $\left(\mathrm{kg} / \mathrm{m}^{3}\right)$.

\begin{tabular}{llllll}
\hline \multirow{2}{*}{ Sample } & \multicolumn{2}{l}{ Dry conditions } & & \multicolumn{2}{l}{$2{ }^{\circ} \mathrm{C}$ and $40 \%$ R.H. conditions } \\
\cline { 2 - 3 } & Raw miscanthus & Crushed miscanthus & Raw miscanthus & Crushed miscanthus & Mineralized miscanthus \\
\hline 1 & 97 & 93 & 111 & 98 & 370 \\
2 & 90 & 90 & 113 & 103 & 371 \\
3 & 91 & 91 & 115 & 103 & 386 \\
Average value & 93 & 91 & 113 & 101 & 376 \\
\hline
\end{tabular}

\subsubsection{Physical characteristics of mineralized miscanthus}

Physical characteristics of the chips, before and after mineralization, have been determined in order to point out the real effect of the mineralization process. A first important characteristic is apparent density: it gives a good idea of the capacity of water (liquid or vapour) penetration into plant aggregates but also thermal insulation properties. For porous materials able to adsorb humidity, it is important to define test conditions (Tab. 1): density has been evaluated in dry conditions and in equilibrium with specific environment $\left(21^{\circ} \mathrm{C}\right.$ and $40 \%$ R.H.).

The granulometry is a second important property for understanding the behavior of chips (Fig. 4): crushed miscanthus chips are quite small and consequently offer a higher specific surface for interaction with water and mineralization. Taking into account the granulometry of the chips, it is obvious that the smallest the dimensions, the highest the absorption rate. That is why chips mineralization induced a significant reduction of water absorption even if apparent and bulk densities are not significantly different.

Sorption actually encompasses two phenomena: absorption and adsorption. Adsorption is the accumulation of molecules on the surface of the solid, whereas

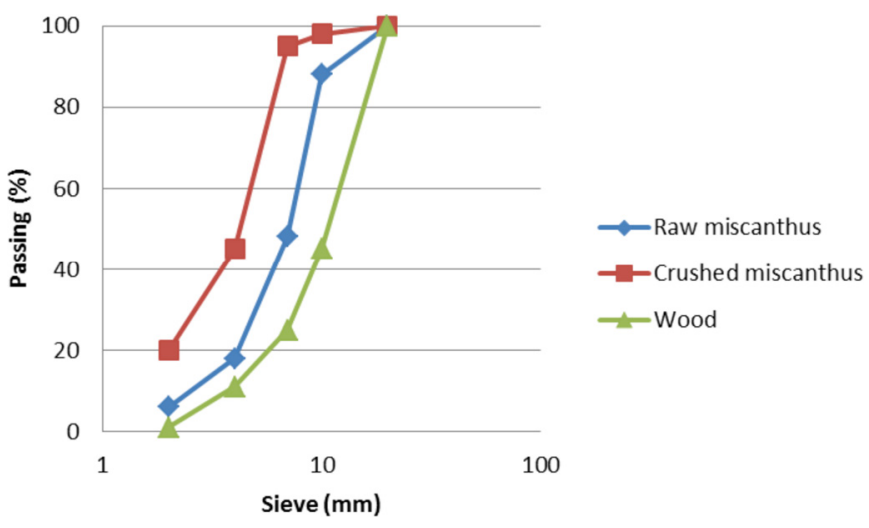

Fig. 4. Sieving curves of chips.

absorption deals with the penetration of liquid into the solid. The adsorption without chemical reaction between molecules of the solid and the liquid is completely reversible and does not alter the structure of the solid. This phenomenon results from electrostatic interactions between molecules and atoms. In the case of miscanthus, rather than forces of Van der Waals or polarization, these are Hydrogen Bridge links which ensure a strong cohesion 


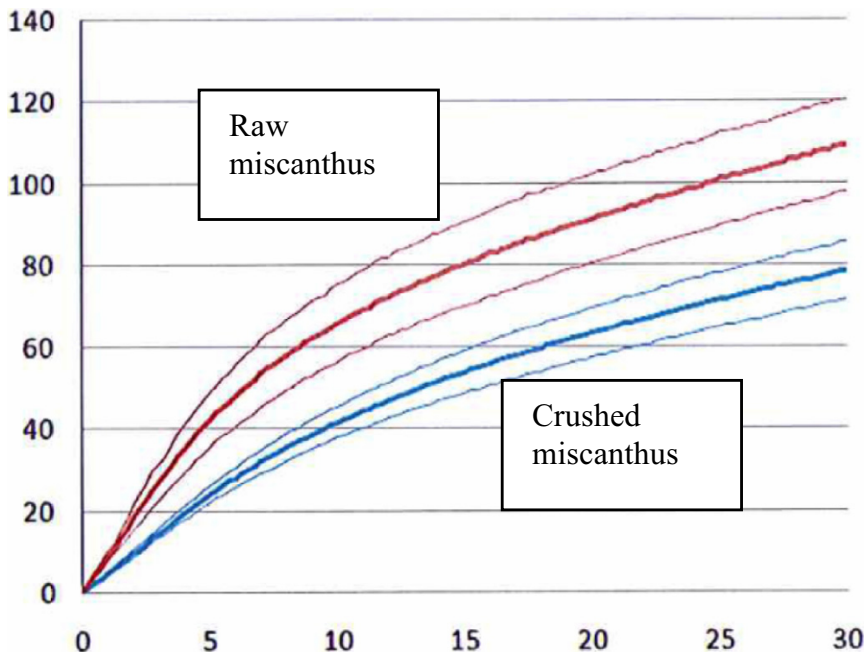

Fig. 5. Coefficient of absorption (\%/dry initial mass) vs. time (s) for raw materials.

between the fibers and micro fibrils composed of cellulose [16]. But it means also that miscanthus based materials are highly hygroscopic.

Water absorption would also give indication on the effect of mineralization. Most commonly tests used to analyze water transfer at the interface is the capillary suction test $[17,18]$. The capillary suction test is described by several standards: they differ essentially by the water level above the bottom surface of concrete specimen and the time when measurement is taken. Mass change is usually registered after 5, 15, 30 and $45 \mathrm{~min}$, as well as after 2, 6 and $24 \mathrm{~h}$. Mass is measured on samples wiped off with a damp tissue. From the capillary suction test, it is possible to calculate the coefficient of water absorption, which is related to the evolution of the mass of the specimen with time [17]. However, it was necessary to adapt the test to chips: samples of particles, after being dried into an oven, are placed in nylon tights under water. The tights let the water go through without losing particles. The measurement of mass variation is not performed on one sample but on a pool, containing several chips to start. The measure may be slightly influenced by the size of the chips.

There is a clear difference in behavior between raw and crushed miscanthus. New test procedure [19] allowed following what really happens in the first minutes of contact between chips and water, because it exactly corresponds to the time of mixing for mineralization process: finest particles offer an absorption rate largely greater than larger particles (Fig. 5).

Mineralization induces a reduction of absorption rate [7]. However, there is a larger dispersion of the results, probably due to an incomplete process: more time should be needed to have a complete mineralization.

\subsection{Concrete blocks preparation}

Concrete blocks are produced with CEM I $52.5 \mathrm{~N}$ with the proportions given in Table 2 .

Mixing procedure for concrete blocks is described hereafter and is inspired by the work realized by Delhez [20]:
Table 2. Mix proportions for miscanthus concrete blocks.

\begin{tabular}{llc}
\hline Components & $\begin{array}{l}\text { Quantity } \\
(\%)\end{array}$ & $\begin{array}{l}\text { Quantity } \\
(\mathrm{g} / \text { block })\end{array}$ \\
\hline Mineralized & 40.54 & 1335 \\
miscanthus aggregates & & \\
Ciment CEM I 52.5 N & 24.32 & 803 \\
Water & 35.14 & 1150 \\
\hline
\end{tabular}

- introduce aggregates and sand into the mixer and mixing for $120 \mathrm{~s}$;

- wait $60 \mathrm{~s}$;

- add cement and mix for 2 min;

- add water and mix for $2 \mathrm{~min}$.

The steps of vibration are as follows (Fig. 6a):

- place the mold on the vibrating table $(50 \mathrm{~Hz})$;

- cast half of the fresh concrete in the cubic metal mold;

- put a mass $( \pm 8 \mathrm{~kg})$ in the mold on the fresh concrete;

- set the vibrating table on for a period of $30 \mathrm{~s}$;

- remove the mass;

- cast the other half of the fresh concrete in mold;

- place the mass of 8 pounds in the mold of the fresh concrete;

- set the vibrating table on for $30 \mathrm{~s}$;

- remove the samples (Fig. $6 \mathrm{~b}$ ).

\section{3 $\mathrm{CO}_{2}$ injection technique}

The objective of the $\mathrm{CO}_{2}$ injection technique procedure is the development of a system able to force carbonation. An air-conditioned room called incubator, with controlled humidity and temperature, will be used. Specific $\mathrm{CO}_{2}$ injection system is connected to the incubator (Fig. 7). The following three parameters can be taken into account by the latter: the temperature, the relative humidity and the percentage of injected $\mathrm{CO}_{2}$. The temperature is controlled using a thermostatically controlled bath while relative humidity is achieved by means of a saline type $\mathrm{Ca}$ $\left(\mathrm{NO}_{3}\right)_{2} \cdot 4 \mathrm{H}_{2} \mathrm{O}$.

According to Thiery [21], accelerated carbonation tests show it is unrealistic to conduct trials with a low $\mathrm{CO}_{2}$ content (less than 5\%) because, at this level, the speed of carbonation is very sensitive to small changes in the $\mathrm{CO}_{2}$ content: that is why he worked with $50 \% \mathrm{CO}_{2}$. Studies by Monkman and Shao [6] suggest the same amount of $\mathrm{CO}_{2}$ in insisting on the fact that, in the air, the $\mathrm{CO}_{2}$ concentration is between $0.03 \%$ and $0.05 \%$. The second study suggests the use of an incubator where the relative humidity is about $60 \%$, which is the most common.

Incubators available in the lab allowed to work with rate of $20 \%$ and commercial $\mathrm{CO}_{2}$ [22].

The principle of the injection test device (Fig. 7) is as follows: the pressure vessel, with a volume of $0.04 \mathrm{~m}^{3}$ and the available pressure of $5 \mathrm{MPa}$, serves as a source of $\mathrm{CO}_{2}$. The mixture of air with carbon dioxide is performed in another container for a volume of $0.3 \mathrm{~m}^{3}$ and a pressure up to $1 \mathrm{MPa}$. The gas mixture is transported by pipes through 
the ceiling of the incubator and the gas diffuses through holes in the ceiling and floor. The constant pressure in the range between 150 and $200 \mathrm{~Pa}$ is maintained in the sealed chamber by the automatic control equipment. The fans are placed inside of the tank and in the rooms, to ensure a constant concentration of carbon dioxide, which is heavier than air. The concentration of $\mathrm{CO}_{2}$ is registered by detection tubes with a precision of $0.5 \%$ [24].

\section{4 $\mathrm{CO}_{2}$ absorption evaluation}

\subsubsection{Mass variation of the sample}

It is possible to quantify $\mathrm{CO}_{2}$ absorption by means of the calculation of the mass variation of the sample, according to Monkman' relationship [6]:

$$
\begin{gathered}
\text { Mass gain }(\%)=\left(\text { mass }_{\text {final }}+\text { mass }_{\text {loss water }}-\text { mass }_{\text {initial }}\right) \\
\text { mass }_{\text {dry binder }}=\Delta \operatorname{mass}_{\mathrm{CO}_{2}} / \text { mass }_{\text {dry binder }}
\end{gathered}
$$

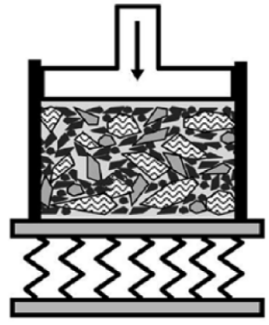

(a)

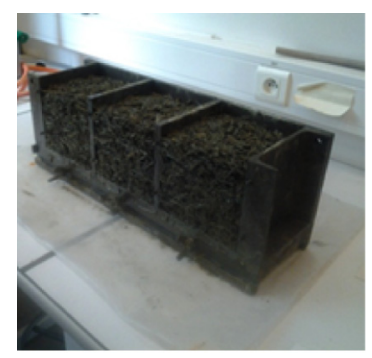

(b)
Fig. 6. preparation of the samples (a) vibration and loading principles and (b) demoulding of the concrete blocks.

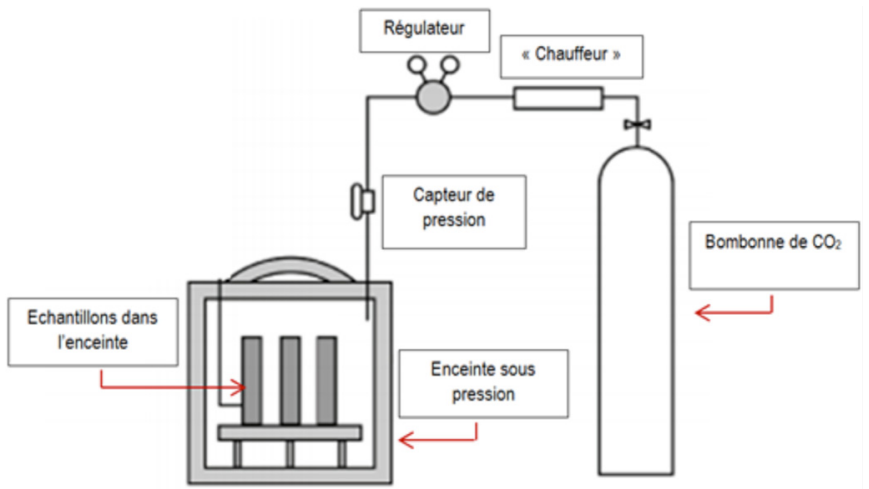

Fig. 7. System for $\mathrm{CO}_{2}$ incubation [23].
The mass of water is taken into account because the test is performed in a closed system: a device is set up to capture water lost by concrete blocks. We assume that the aggregates are inert in relation to the capture of $\mathrm{CO}_{2}$. The mass of the sample is measured after 1,3 and $7 \mathrm{~h}$ for the first tests in order to avoid too often opening the incubator. The measurement is made after $16,24,32$ and $48 \mathrm{~h}$, respectively.

During the introduction of concrete blocks in the incubator, they will reject water; discharged water is measured using silica gel, whose main property is to capture the water in a wet environment. The silica gel will capture the concrete blocks water but also water from saline solution. This absorption is evaluated on the base of the change in mass of silica gel 1 day left in the incubator without concrete blocks in the curing conditions of accelerated carbonation $(60 \%$ relative humidity and $20 \% \mathrm{CO}_{2}$ injected).

\subsubsection{Thermogravimetry analysis}

Thermogravimetry analysis (TG-DSC) is obtained from thermogravimetry (TG) combined with Differential Scanning Calorimetry (DSC). It allows registering carbonation by thermal dissociation of calcium hydrates and carbonates [21].

\section{Results and discussions}

\subsection{Carbonation of miscanthus aggregates}

After mineralization process which includes cement, silica fume, $\mathrm{CaCl}_{2}$ and superplasticizer, miscanthus aggregates are stored into incubator (Fig. 7) for $7 \mathrm{~h}$ and mass increase is registered for 1,3 and $7 \mathrm{~h}$, respectively. Aggregates are disposed in such a way that $\mathrm{CO}_{2}$ is able to diffuse from all the faces.

Quantification of $\mathrm{CO}_{2}$ gain mass (Tab. 3) is based on Monkman equation (Eq. (5)).

The initial and final masses are obtained by registering mass performed every $\mathrm{x}$ hours (Tab. 4). The loss of mass of water is obtained for all of the samples, by summing the increase of masses of silica gel and saline (both water absorber). Thus, we can get the mass of water lost in the samples as equivalent to that captured by the silica gel and saline simultaneously. The calculation is as follows (Eq. (6)):

$$
\begin{aligned}
& \text { Mass }_{\text {water lost }}=\text { Final mass } \\
&+ \text { finalica gel mass } \\
&-(\text { initialine solution } \\
&+ \text { initial mass } \\
& \text { silica gel } \\
&\text { saline solution }) .
\end{aligned}
$$

Table 3. Quantification of $\mathrm{CO}_{2}$ absorption by miscanthus aggregates.

\begin{tabular}{lcccr}
\hline Variables & Sample 1 & Sample 2 & Sample 3 & Total \\
\hline Initial mass (g) & 363.52 & 422.34 & 325.37 & 1111.23 \\
Final mass (g) & 363.20 & 421.95 & 325.06 & 1110.21 \\
Water loss mass (g) & 6.34 & 7.37 & 5.68 & 19.40 \\
Dry binder mass (g) & 118.80 & 138.02 & 106.33 & 363.15 \\
Mass gain (\%) & 5.07 & 5.06 & 5.05 & 5.06 \\
\hline
\end{tabular}


Table 4. $\mathrm{CO}_{2}$ mass gain (\%) vs. time.

\begin{tabular}{llll}
\hline Time & \multicolumn{3}{l}{ Mass gain $(\%)$} \\
\cline { 2 - 4 } & Sample 1 & Sample 2 & Sample 3 \\
\hline $1 \mathrm{~h}$ & 1.32 & 1.29 & 1.36 \\
$3 \mathrm{~h}$ & 2.92 & 2.86 & 2.91 \\
$7 \mathrm{~h}$ & 5.06 & 5.06 & 5.05 \\
\hline
\end{tabular}

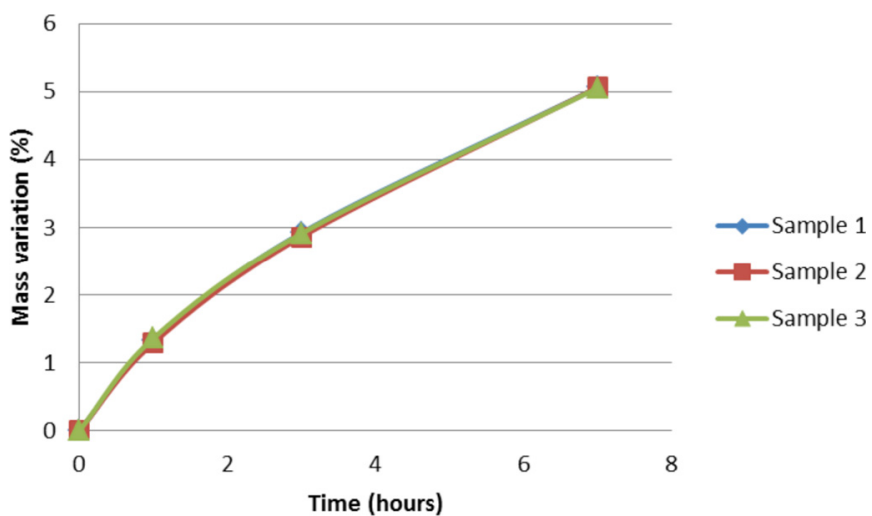

Fig. 8. Evolution of $\mathrm{CO}_{2}$ capture vs. time.

Calculation of water lost for all the samples is: $208.2+2436.6-(200+2425.4)=19.4 \mathrm{~g}$.

The assumption is made that the sample loses water in proportion to its mass. Indeed, there are three samples in the incubator, it does not seem correct to say that each sample loses one third of the total water. Indeed, since the sample 1 represents $32.71 \%$ mass of all samples in the incubator, we consider that the mass of water lost by the sample is $32.71 \%$ of the mass of water lost by all samples. Thus, the mass of water lost by the sample 1 is calculated as follows: $(32.71 / 100) \times 19.4=6.34 \mathrm{~g}$.

As we exactly know the quantity of cement used for mineralization, it is possible to know the mass of dry binder (Eq. (7)):

$$
\text { Mass }_{\text {dry binder }}=\text { percentage }_{\text {theory }} \times \text { mass }_{\text {initial }} .
$$

For example, for sample 1, it gives: $(32.68 / 100) \times 363.52$ $=118.80 \mathrm{~g}$

The mass gain calculated with equation (7) is around $5 \%$, with a good reproducibility.

Another interesting item is to verify how fast and long is $\mathrm{CO}_{2}$ diffusion with time (Tab. 4).

We note a good reproducibility of results and we find that the absorption of $\mathrm{CO}_{2}$ is increasing with time (Fig. 8).

Moreover, we note that miscanthus carbonated aggregates are more resistant to wear than those who were not carbonated (Tab. 5): carbonated chips have a Micro-Deval coefficient of about 7.23, while those who were not carbonated get a coefficient approaching 12.69, which corresponds to a higher loss of mass during attrition process. We can say that the $\mathrm{CO}_{2}$ capture on plant fibers miscanthus type is positive from mechanical point of view and should positively influence the compressive strength of blocks.
Table 5. Micro-Deval value for miscanthus.

\begin{tabular}{lllll}
\hline Material & \multicolumn{4}{l}{ Micro-Deval coefficient } \\
\cline { 2 - 5 } & Sample 1 & Sample 2 & Sample 3 & Average \\
\hline $\begin{array}{l}\text { Miscanthus } \\
\text { aggregagtes }\end{array}$ & 12.04 & 12.84 & 13.19 & 12.69 \\
$\begin{array}{l}\text { Carbonated } \\
\text { miscanthus }\end{array}$ & 7.98 & 6.70 & 7.01 & 7.23 \\
aggregates & & & & \\
\hline
\end{tabular}

Table 6. Compressive strength of concrete blocks.

\begin{tabular}{|c|c|c|c|}
\hline \multirow[t]{2}{*}{ Test } & \multicolumn{2}{|c|}{ Compressive strength $\left(\mathrm{N} / \mathrm{mm}^{2}\right)$} & \multirow{2}{*}{$\begin{array}{l}\mathrm{CO}_{2} \text { mass } \\
\text { gain }(\%)\end{array}$} \\
\hline & Wet curing & $\mathrm{CO}_{2}$ curing & \\
\hline \multicolumn{4}{|c|}{ Miscanthus aggregates } \\
\hline 1 & 0.0091 & 0.0522 & 1.49 \\
\hline 2 & 0.0091 & 0.0689 & 1.14 \\
\hline 3 & 0.0091 & 0.0546 & 1.36 \\
\hline Average & 0.0091 & 0.0586 & 1.33 \\
\hline \multicolumn{4}{|c|}{ Carbonated miscanthus aggregates } \\
\hline 1 & 0.0275 & 0.202 & 1.43 \\
\hline 2 & 0.0285 & 0.209 & 1.23 \\
\hline 3 & 0.0314 & 0.205 & 1.37 \\
\hline Average & 0.0290 & 0.205 & 1.34 \\
\hline
\end{tabular}

\subsection{Effect of carbonation on concrete blocks}

Concrete blocks were stored in two types of curing conditions during $7 \mathrm{~h}$ :

- wet climatic room (100\% R.H.);

- incubator with $20 \% \mathrm{CO}_{2}$.

Compressive strength of blocks (Tab. 6) is five times higher when stored in $\mathrm{CO}_{2}$ incubator, even if it is quite low. But the objective is to obtain insulation materials and not structural elements. The average compressive strength of these blocks (Tab. 6) is almost seven times as large as the blocks stored in a humid chamber. It is also four times greater than that of concrete blocks made from noncarbonated mineralized miscanthus.

\subsection{Comparison of $\mathrm{CO}_{2}$ absorption methods}

In order to compare the two methods of quantifying $\mathrm{CO}_{2}$ absorption, tests have been performed on the same samples (Tab. 7). Comparison is based on cubes stored for a longer period.

Absorption of $\mathrm{CO}_{2}$ by TG is quantified by calculating the difference between the percentage of $\mathrm{CO}_{2}$ in the original sample and the percentage of $\mathrm{CO}_{2}$ in the sample after storage in incubator. 
Table 7. $\mathrm{CO}_{2}$ mass gain for concrete blocks (calculation).

\begin{tabular}{ll}
\hline Test & $\mathrm{CO}_{2}$ mass gain $(\%)$ \\
\hline 1 & 3.07 \\
2 & 2.98 \\
3 & 2.95 \\
& \\
Average & 3.00 \\
\hline
\end{tabular}

Table 8. $\mathrm{CO}_{2}$ mass gain for concrete blocks (TG-DSC).

\begin{tabular}{lll}
\hline Situation & $\begin{array}{l}\text { Depth in the } \\
\text { block }(\mathrm{cm})\end{array}$ & $\begin{array}{l}\mathrm{CO}_{2} \text { mass } \\
\text { gain }(\%)\end{array}$ \\
\hline $\begin{array}{l}\text { Initial } \\
8 \mathrm{~h} \text { incubator - center }\end{array}$ & - & 0 \\
$\begin{array}{l}\text { of the block } \\
\begin{array}{l}\text { h incubator - middle } \\
\text { of the block }\end{array}\end{array}$ & 4 & 1.21 \\
$\begin{array}{l}\text { 8 h incubator - edge } \\
\text { of the block }\end{array}$ & 0 & 4.61 \\
\hline
\end{tabular}

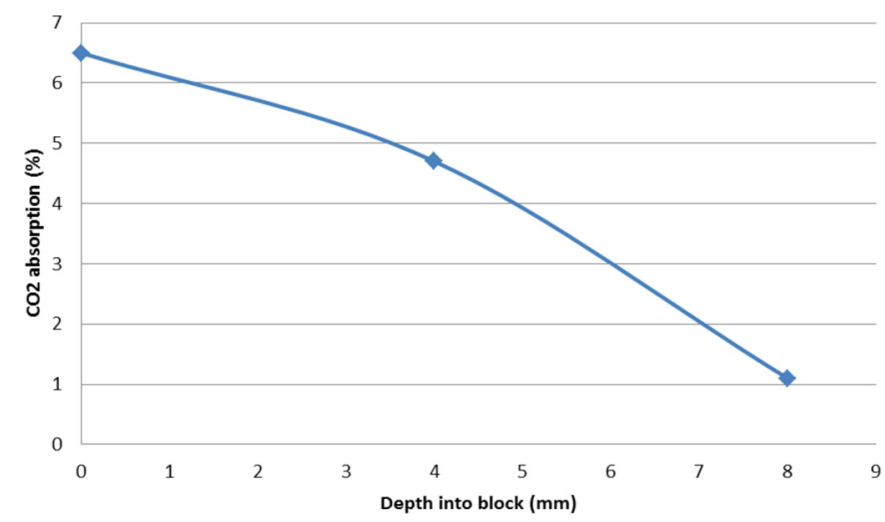

Fig. 9. Evolution of $\mathrm{CO}_{2}$ absorption rate with depth.

Samples are taken from different parts of the block (Tab. 8).

Results seem to be coherent as $\mathrm{CO}_{2}$ penetration is depending on the depth inside the block (Fig. 9). This phenomenon was previously observed [21].

The results obtained by mass variation measurement showed a percentage of $\mathrm{CO}_{2}$ in the range of $3 \%$, which corresponds to what is obtained by thermogravimetry as average value between the three samples. According to the investigation carried out here above, the results obtained by mass variation measurement correspond to a sample taken at $6 \mathrm{~cm}$ from the end of the block.

Measurement by mass variation does not seem to be excessive compared with those carried out by thermogravimetry.

We therefore conclude that the mass variation measurement, much less expensive in terms of time and money than the TG, is a good approach for quantifying $\mathrm{CO}_{2}$ absorption and validates the results of the investigations previously established.

\section{Conclusions}

On the basis of the experimental results, the following conclusions can be drawn:

- capture of $\mathrm{CO}_{2}$ in concrete blocks proves to be a good alternative for the environment and, more specifically, in the fight against global warming through limiting greenhouse gas emissions;

- use of bio sourced materials like miscanthus requires a mineralization process in order to guarantee a minimum of rigidity and to reduce water absorption capacity;

- mineralization implies a better resistance to abrasion, which is profitable during mixing operations;

- carbonation of bio sourced aggregates before concrete blocks production can increase concrete blocks performances;

- the strength of concrete blocks is increased by using $\mathrm{CO}_{2}$ injection, with regard to classic humid curing;

- quantification of $\mathrm{CO}_{2}$ absorption maybe proceeded by measuring mass variation of the sample or by TG. This last procedure helps us to observe the rate of $\mathrm{CO}_{2}$ penetration into concrete wall;

- the mass variation measurement, much less expensive in terms of time and money than the TG, remains nevertheless a good approach for quantifying $\mathrm{CO}_{2}$ absorption.

Optimization of $\mathrm{CO}_{2}$ injection process is however needed, taking into account carbon dioxide concentration and humidity, in order to increase strength performances of concrete blocks.

\section{References}

1. L. Courard, P. Teller, Environmental evaluation of building materials and processes: application of life cycle analysis to the construction of industrial hall, Mater. Struct. 34, 404 (2001)

2. L. Courard, A. Darimont, M. Schouterden, F. Ferauche, X. Willem, R. Degeimbre, Durability of mortars modified with metakaolin, Cement Concr. Res. 33, 1473 (2003)

3. Y. Shao, M.S. Mirza, X. Wu, $\mathrm{CO}_{2}$ sequestration using calcium silicate concrete, Can. J. Civil Eng. 33, 776 (2006)

4. H. Toennies, J.J. Shideler, Plant drying and carbonation concrete block - NCMA-PCA cooperative program, J. Am. Concr. Inst. 60, 617 (1963)

5. J.F. Young, R.L. Berger, J. Bresse, Accelerated curing of compacted calcium silicate mortars on exposure to $\mathrm{CO}_{2}$, J. Am. Ceram. Soc. 57, 394 (1974)

6. S. Monkman, Y. Shao, Assessing behaviour of cementitious materials, J. Mater. Civil Eng. 18, 768 (2006)

7. L. Courard, A. Darimont, A. Louis, F. Michel, Mineralization of bio-based materials: effect on cement-based mix properties, Bull. Polytech. Inst. Iassi (Romania) LIV, 14 (2012)

8. F. Debieb, L. Courard, S. Kenai, R. Degeimbre, Roller compacted concrete with contaminated recycled aggregates, Constr. Build. Mater. 23, 3382 (2009)

9. M.R.F. Gonçalves, C.P. Bergmann, Thermal insulators made with rice husk ashes: production and correlation between properties and microstructure, Constr. Build. Mater. 21, 2059 (2007) 
10. S. Elfordy, F. Lucas, F. Tancret, Y. Scudeller, L. Goudet, Mechanical and thermal properties of lime and hemp concrete ("hempcrete") manufactured by a projection process, Constr. Build. Mater. 22, 2116 (2008)

11. P.B. de Bruijn, K.H. Jeppsson, K. Sandin, C. Nilsson, Mechanical properties of lime-hemp concrete containing shives and fibres, Bio Syst. Eng. 103, 474 (2009)

12. J.L. Philippou, S.P. Karastergiou, Lignocellulosic materials from annual plants and agricultural residues as raw materials for composite building materials, in Proceedings of the International Conference: FOREST RESEARCH: A Challenge For an Integrated European Approach (K. Radoglou, ed., 2001), pp. 817-822

13. K. Kaack, K.U. Schwarz, P.E. Brander, Variation in morphology, anatomy and chemistry of stems of Miscanthus genotypes differing in mechanical properties, Ind. Crops Prod. 17, 131 (2003)

14. R. Grimont, A study of the mineralization and the adhesion in wooden concrete, Master thesis, Faculty of Applied Sciences, Université de Liège, Belgium, 2008, p. 142 (in French)

15. J. Rossolen, Contribution to the study of bio-based aggregates and application to miscanthus concrete, Master thesis, Faculty of Applied Sciences, Université de Liège, Belgium, 2010, p. 126 (in French)

16. B. Zhang, Q. Wu, L. Wang, G Hang, Characterization of internal void structure of strand-based wood composites using X-ray tomography and digital tools, in Proceedings of McMat2005: 2005 Joint ASME/ASCE/SES Conference on Mechanics and Materials, June 1-3 (Baton Rouge, Louisiana, USA, 2005)
17. L. Courard, R. Degeimbre, A capillary suction test for a better knowledge of adhesion process in repair technology, Can. J. Civil Eng. 30, 1101 (2003)

18. H. Justnes, Capillary suction of water by polymer cement mortars, in Proceedings of the RILEM Symposium on Properties and Test Methods for Concrete-Polymer Composites (ICPIC, D. Van Gemert, ed., Oostende, 1995), pp. 29-37

19. L. Courard, Adhesion of repair systems to concrete: influence of interfacial topography and transport phenomena, Mag. Concr. Res. 57, 273 (2005)

20. L. Courard, F. Michel, P. Delhez, Use of concrete road recycled aggregates for roller compacted concrete, Constr. Build. Mater. 24, 390 (2010)

21. M. Thiery, Modélisation de la carbonatation atmosphérique des matériaux cimentaires: Prise en compte des effets cinétiques et des modifications microstructurales et hydriques (Modelling of atmospheric carbonation of cementitious materials: Consideration of kinetic effects and microstructural changes), $\mathrm{PhD}$ thesis, Ecole nationale des ponts et chaussées, France, 2005, p. 331 (in French)

22. V. Parmentier, F. Michel, L. Courard, $\mathrm{CO}_{2}$ captation in recycled based aggregates concrete blocks. Journées scientifiques du Regroupement Francophone pour la Recherche et la Formation dans le domaine du béton, Sherbrooke (22-23 aoUtt 2013), 2013, p. 10 (in French)

23. V. Parmentier, Study of the captation of $\mathrm{CO}_{2}$ in miscanthus and recycled aggregates based concrete blocks, Master thesis, Faculty of Applied Sciences, Université de Liège, Belgium, 2012, p. 136 (in French)

24. J. Jerga, Physico-mechanical properties of carbonated concrete, Constr. Build. Mater. 8, 645 (2004)

Cite this article as: L. Courard and V. Parmentier: Carbonated miscanthus mineralized aggregates for reducing environmental impact of lightweight concrete blocks. Sust. Build. 2, 3 (2017). 